\title{
O COMPORTAMENTO DO CONSUMIDOR NO MERCADO DE BARRAS DE CEREAIS
}

\author{
CONSUMER BEHAVIOR IN THE MARIET OF CEREAL BARS \\ DEGÁSPARI, Cláudia Helena ${ }^{1}$; \\ MOTTIN, Fátima²; \\ BLINDER, Elsa Wasserman ${ }^{3}$
}

Recebido para publicação em 11/11/2008

Aceito para publicação em 06/05/2009

\begin{abstract}
RESUMO
O objetivo deste trabalho foi descrever o comportamento do consumidor e do não consumidor de barras de cereais, identificando o público ao qual a promoção do produto deve ser direcionada de forma a estimular o seu consumo. Foram entrevistadas 232 pessoas, sendo que $63,8 \%$ se identificaram como consumidores do produto e, na maioria, mulheres $(73,8 \%)$. Foram analisadas as tendências de consumo de acordo com o estado civil, faixa etária, nível de renda, grau de escolaridade, prática de exercícios físicos, motivos que levam ao consumo e local de compra. Verificou-se que na compra do produto a escolha é muito impulsionada pelo sabor e textura, seguida pelos dados dos valores nutricionais. Preço, marca, fabricante e embalagem mostraram uma baixa interferência na decisão de compra. O local preferencial de compra são os supermercados. Não existe uma classe social que consuma expressivamente mais que outra quando se analisam conjuntamente renda, idade e escolaridade. O motivo de consumo se diferencia de acordo com a faixa etária, sendo que para os idosos a palavra "saudável" está altamente associada ao produto. Tendo em vista as tendências observadas quanto ao local de compra desse produto, a forma mais indicada para a sua promoção seria aquela realizada nos pontos de venda, em vez de se fazer um investimento (por vezes oneroso) em propagandas televisivas.

Palavras-chaves: Comportamento do consumidor. Barras de cereais. Alimentos.
\end{abstract}

\footnotetext{
ABSTRACT

The aim of this study was to describe the behavior of consumers and non-consumers of cereal bars in order to identify the target public to which

${ }^{1}$ Professora Adjunta da Universidade Tuiuti do Paraná. Rua Com. Fontana, 405, ap. 803 - 80030-070 - Curitiba - PR

e-mail: sensus@cwb.matrix.com.br fone: (41) 84014490

${ }^{2}$ Consultora Estatística da Empresa Painel Pesquisas. E-mail: mottin_fatima@hotmail.com

${ }^{3}$ Aluna de Graduação do Curso de Nutrição da Universidade Tuiuti do Paraná. E-mail: elsawb@hotmail.com
} 
the product should be addressed. Of the 232 subjects interviewed, $63 \%$ were consumers of cereal bars and $73.8 \%$ were women. The consumption trends were analyzed with respect to marital status, age group, income, educational level, physical exercise, reasons for and place of purchase. It was observed that the purchase of the product is driven primarily by its flavor, followed by its nutritional value. The price, the brand, the manufacturer and the packaging showed a small influence in the decision to purchase the product. The preferred place of purchase was the supermarket. When accounting for income, age and educational level, there were no distinctions in consumption among social groups. The reasons for purchase varied among age groups: For the elderly, the product was associated with the word "healthy," while for the middle aged and youngsters, it was associated with "practicality" and the desire to "stay in shape". Based on the data, it is best to promote this product.

Keywords: Consumer behavior. Cereal bars. Food.

\section{Introdução}

Entender as necessidades do consumidor é um dos princípios básicos do marketing. E o de que mais as pessoas precisam hoje, para além da relação de compra, são relacionamentos positivos com a marca. Especialistas ouvidos pelo Mundo do Marketing são unânimes em destacar três requisitos essenciais na relação entre as empresas e seus clientes: confiança, diálogo e reconhecimento. (MELLO, 2006).

Alguns especialistas são categóricos em afirmar que nem mesmo o consumidor sabe o que quer. Por isso, toda empresa deve estar atenta para atender as demandas reprimidas. Mas, num cenário em que produtos e serviços são semelhantes, o que vai diferenciar determinada marca da outra é a experiência positiva proporcionada em todos os contatos com um produto ou serviço. (MELLO, 2006).

Decifrar os anseios e desejos dos consumidores em relação a um produto requer um estudo detalhado, onde inúmeras variáveis são encontradas, entre elas a confiabilidade no produto, seu preço, sua qualidade e principalmente sua aparência. No entanto, uma das características mais destacadas e decisivas no momento da compra está na identificação do produto com o consumidor sob o ponto de vista social. (OLIVEIRA, 2006).

Numa determinada sociedade, certas características são mais valorizadas que outras, sendo que os aspectos sociais sempre se encontram ligados aos mecanismos mercadológicos. Para que o ato de aquisição seja concretizado, o consumidor deve estabelecer uma identificação com o produto. A escolha é, muitas vezes, influenciada pelas informações recebidas no dia a dia, ou seja, pelos costumes da comunidade e principalmente pelos apelos de promoção do produto na mídia. Neste caso, cada produto deve ser promovido por meios específicos de acordo com suas características básicas, embora seja quase impossível prever a reação dos consumidores diante dos apelos. (OLIVEIRA, 2006).

Identificar o comportamento do consumidor é de importância estratégica no que diz respeito a adequar os produtos às suas necessidades e anseios. Dentro desta perpectiva, nossa pesquisa teve como objetivo levantar características do comportamento de consumidores de barras de cereais e, com base nos seus resultados, apontar as formas adequadas de promoção deste produto nos diversos segmentos de mercado que o consomem.

\section{Materiais e métodos}

Para o desenvolvimento deste projeto de pesquisa, aprovado pelo Comitê de Ética em Pesquisa em Humanos e Animais da Universidade Tuiuti do Paraná, foi realizado um estudo descritivo a partir dos dados colhidos na aplicação de um questionário com 13 perguntas fechadas, encadeadas, e apenas uma aberta, todas relativas ao tema "consumo de barras de cereais" (Anexo 1), para saber quais as razões que levam as pessoas a consumirem barras de cereais. Os dados foram tratados por uma adequada análise estatística. 
A amostragem utilizada neste trabalho compunha-se de amostras não probabilísticas ou intencionais, que tentam reproduzir o mais fielmente possível a população. (TRIOLA, 1999).

Empregou-se a amostragem não probabilística por quotas. Nesse tipo de amostra o universo a ser estudado é dividido em subuniversos e a amostra total é distribuída entre os subuniversos, respeitando suas proporções. Os entrevistadores fazem a seleção dos respondentes para cobrir suas cotas. (TRIOLA, 1999).

Foram entrevistadas 232 pessoas, entre consumidores e não consumidores de barras de cereais, e os locais de coleta dos dados foram a Universidade, supermercados e empresas na cidade de Curitiba, tornando bem amplo o público alvo. Os dados coletados foram analisados estatisticamente para se subsidiar uma interpretação científica. (TRIOLA, 1999; AMERINE, PANGBORN, ROESSLER, 1965)

Para a análise da pesquisa empregou-se a estatística descritiva e o teste qui-quadrado $\left(\chi^{2}\right)$. $O$ teste $\chi^{2}$, aplicável em dados representados em forma de frequência, é utilizado para detectar significância estatística da diferença entre dois grupos independentes:

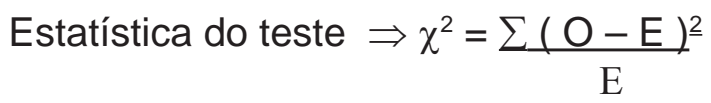

Onde: $\mathrm{O}=$ Frequência observada

$\mathrm{E}=$ Frequência esperada

O teste $\chi^{2}$ é uma estatística não paramétrica de fácil compreensão e muito usado para verificar se há diferença entre frequências esperadas e frequências observadas de duas ou mais categorias. No caso, a frequência esperada é sempre aquela que determina a igualdade dos grupos. O teste confronta a frequência esperada com a observada, e se forem verificadas diferenças significativas entre as duas categorias, os grupos são considerados diferentes.

\section{Resultados e discussão}

Foram entrevistadas 232 pessoas, entre consumidores e não consumidores de barras de cereais, no período compreendido entre 16 de outubro e 09 de novembro de 2007, na cidade de Curitiba. O objetivo era descrever o comportamento do consumidor e do não consumidor, identificando o público ao qual a promoção do produto deve ser direcionada de forma a estimular o seu consumo.

Pode-se verificar no Quadro 01 que, dos 232 entrevistados, $63,8 \%$ consomem barras de cereais e que as mulheres consomem mais $(73,8 \%)$ deste produto que os homens $(51,9 \%)$.

Quadro 01 - Consumo de barras de cereais por sexo

\begin{tabular}{|c|c|c|c|}
\hline SEXO & $\begin{array}{c}\text { NÃO } \\
\text { CONSOME }\end{array}$ & CONSOME & TOTAL \\
\hline Feminino & $26,2 \%$ & $73,8 \%$ & $100,0 \%$ \\
\hline Masculino & $48,1 \%$ & $51,9 \%$ & $100,0 \%$ \\
\hline Total & $36,2 \%$ & $63,8 \%$ & $100,0 \%$ \\
\hline
\end{tabular}

Sob o ponto de vista do estado civil, os dados não mostram nenhuma tendência de consumo, já que se verifica que todas as situações apresentam um percentual que varia entre $60 \%$ e $80 \%$, conforme observado no Quadro 02.

Quadro 02 - Consumo de barras de cereais por estado civil

\begin{tabular}{|c|c|c|c|}
\hline $\begin{array}{c}\text { ESTADO } \\
\text { CIVIL }\end{array}$ & $\begin{array}{c}\text { NÃO } \\
\text { CONSOME }\end{array}$ & CONSOME & TOTAL \\
\hline Solteiro & $36,8 \%$ & $63,2 \%$ & $100,0 \%$ \\
\hline Casado & $39,3 \%$ & $60,7 \%$ & $100,0 \%$ \\
\hline Outros & $21,4 \%$ & $78,6 \%$ & $100,0 \%$ \\
\hline Total & $35,9 \%$ & $64,1 \%$ & $100,0 \%$ \\
\hline
\end{tabular}

A proporção do público consumidor deste produto não se diferencia no que diz respeito às faixas etárias, pois os percentuais variaram de $50 \%$ a 70\%, de acordo com o Quadro 03. Possivelmente isso ocorra devido à ideia que o produto passa de ser um alimento natural, atingindo assim tanto um

Quadro 03 - Consumo de barras de cereais por faixa etária.

\begin{tabular}{|c|c|c|c|}
\hline $\begin{array}{c}\text { FAIXA } \\
\text { ETÁRIA }\end{array}$ & $\begin{array}{c}\text { NÃO } \\
\text { CONSOME }\end{array}$ & CONSOME & TOTAL \\
\hline 15 a 24 anos & $38,8 \%$ & $61,2 \%$ & $100,0 \%$ \\
\hline 25 a 34 anos & $34,2 \%$ & $65,8 \%$ & $100,0 \%$ \\
\hline 35 a 44 anos & $30,9 \%$ & $69,1 \%$ & $100,0 \%$ \\
\hline 45 a 55 anos & $47,8 \%$ & $52,2 \%$ & $100,0 \%$ \\
\hline $\begin{array}{c}\text { Mais de 55 } \\
\text { anos }\end{array}$ & $37,5 \%$ & $62,5 \%$ & $100,0 \%$ \\
\hline Total & $36,2 \%$ & $63,8 \%$ & $100,0 \%$ \\
\hline
\end{tabular}


público mais idoso, que se alimenta devido a indicações nutricionais de um médico ou nutricionista, como o público jovem, que busca alimentos de consumo rápido.

Considerando-se o nível de renda dos entrevistados, verifica-se no Quadro 04 que aqueles que apresentam maior poder aquisitivo (acima de 10 salários mínimos) têm um percentual de consumo de $75,7 \%$, seguido pelo grupo com nível de renda na faixa de 3 a 5 salários mínimos. Os dados não mostram uma forte tendência, pois se constata que o menor percentual de consumidores encontra-se na faixa de 5 a 10 salários mínimos, ou seja, entre as duas faixas de maior consumo.

Quadro 04 - Consumo de barras de cereais por renda.

\begin{tabular}{|c|c|c|c|}
\hline $\begin{array}{c}\text { FAIXA DE } \\
\text { RENDA }\end{array}$ & $\begin{array}{c}\text { NÃO } \\
\text { CONSOME }\end{array}$ & CONSOME & TOTAL \\
\hline Até 3 sm & $38,8 \%$ & $61,2 \%$ & $100,0 \%$ \\
\hline 3 a 5 sm & $29,4 \%$ & $70,6 \%$ & $100,0 \%$ \\
\hline De 5 a 10 sm & $48,6 \%$ & $51,4 \%$ & $100,0 \%$ \\
\hline $\begin{array}{c}\text { Mais de } 10 \\
\text { sm }\end{array}$ & $24,3 \%$ & $75,7 \%$ & $100,0 \%$ \\
\hline Total & $35,8 \%$ & $64,2 \%$ & $100,0 \%$ \\
\hline
\end{tabular}

Tendo por referência o grau de escolaridade, o Quadro 05 mostra que os consumidores são pessoas com mais alto grau de escolaridade, ou seja, apresentam no mínimo formação de $2^{\circ}$ grau. Entre as pessoas com apenas $1^{\circ}$ grau completo, a maioria não consome o produto $(57,1 \%)$.

Quadro 05 - Consumo de barras de cereais por escolaridade.

\begin{tabular}{|c|c|c|c|}
\hline ESCOLARIDADE & $\begin{array}{c}\text { NÃO } \\
\text { CONSOME }\end{array}$ & CONSOME & TOTAL \\
\hline $1^{\circ} \mathrm{Grau}$ & $57,1 \%$ & $42,9 \%$ & $100,0 \%$ \\
\hline $2^{\circ} \mathrm{Grau}$ & $35,6 \%$ & $64,4 \%$ & $100,0 \%$ \\
\hline $3^{\circ} \mathrm{Grau}$ & $34,8 \%$ & $65,2 \%$ & $100,0 \%$ \\
\hline Total & $35,7 \%$ & $64,3 \%$ & $100,0 \%$ \\
\hline
\end{tabular}

A realização de exercícios físicos não influencia no consumo de barras, conforme exibido no Quadro 06. Em todos os casos, observando-se a prática ou não de algum tipo de exercício físico, o percentual de consumo é aproximadamente igual, variando de $61 \%$ a $68 \%$.
Quadro 06 - Consumo de barras de cereais pela prática de exercícios físicos.

\begin{tabular}{|c|c|c|c|}
\hline $\begin{array}{c}\text { PRÁTICA DE } \\
\text { EXERCÍCIOS } \\
\text { FÍSICOS }\end{array}$ & $\begin{array}{c}\text { NÃO } \\
\text { CONSOME }\end{array}$ & CONSOME & TOTAL \\
\hline $\begin{array}{c}\text { Sim, frequento } \\
\text { academia }\end{array}$ & $37,8 \%$ & $62,2 \%$ & $100,0 \%$ \\
\hline $\begin{array}{c}\text { Sim, faço } \\
\text { caminhadas } \\
\text { regularmente }\end{array}$ & $32,4 \%$ & $67,6 \%$ & $100,0 \%$ \\
\hline $\begin{array}{c}\text { Às vezes faço } \\
\text { exercício } \\
\text { ou caminhada }\end{array}$ & $38,6 \%$ & $61,4 \%$ & $100,0 \%$ \\
\hline $\begin{array}{c}\text { Não faço } \\
\text { exercício }\end{array}$ & $31,7 \%$ & $68,3 \%$ & $100,0 \%$ \\
\hline Total & $35,7 \%$ & $64,3 \%$ & $100,0 \%$ \\
\hline
\end{tabular}

Analisando os motivos que levam ao consumo de barras de cereais, observa-se, pelo Quadro 07, que o número mais elevado de respostas está em procurar as barras de cereais como um "alimento para disfarçar a fome" $(35,1 \%)$, seguido por três outros motivos, com aproximadamente o mesmo percentual, em torno de $27 \%$, que são: "por ser mais saudável", "sem motivo" e "na hora do lanche".

Quadro 07 - Motivo do consumo de barras de cereais.

\begin{tabular}{|c|c|c|}
\hline $\begin{array}{c}\text { MOTIVO DO } \\
\text { CONSUMO }\end{array}$ & TOTAL & \%* \\
\hline Para disfarçar a fome & 52 & $35,1 \%$ \\
\hline Por ser mais saudável & 40 & $27,0 \%$ \\
\hline Sem motivo & 40 & $27,0 \%$ \\
\hline Na hora do lanche & 39 & $26,4 \%$ \\
\hline Por hábito & 23 & $15,5 \%$ \\
\hline $\begin{array}{c}\text { Devido a regime e/ou } \\
\text { dieta }\end{array}$ & 13 & $8,8 \%$ \\
\hline Para manter a forma & 7 & $4,7 \%$ \\
\hline $\begin{array}{c}\text { Antes ou após } \\
\text { exercício }\end{array}$ & 7 & $4,7 \%$ \\
\hline Por alguma doença & 1 & $0,7 \%$ \\
\hline Outros & 1 & $0,7 \%$ \\
\hline Total de entrevistados & 148 & - \\
\hline
\end{tabular}

*Pergunta de múltipla escolha, onde se teve um total de 223 respostas. Porém a análise é feita em cima do total de entrevistados 148, pois uma pessoa pode consumir um produto por mais de um motivo. 
Um ponto muito interessante a ser frisado é que a compra do produto ocorre impulsionada pelo "sabor e textura" (56,8\%), apesar de, nas propagandas, os produtos sempre passarem a ideia de serem um alimento saudável. Em segundo lugar, com um percentual bem mais baixo $(23,6 \%)$, aparecem aqueles que compram devido aos "valores nutricionais" apresentados pelo produto. O preço, a marca, o fabricante e a embalagem mostraram uma baixa interferência na hora da decisão de compra do produto, de acordo com o exibido no Quadro 08.

Quadro 08 - Motivo da escolha da barra de cereais no momento da compra.

\begin{tabular}{|c|c|c|}
\hline MOTIVO DA ESCOLHA & TOTAL & \%* \\
\hline Pelo sabor e textura & 84 & $56,8 \%$ \\
\hline Pelos valores nutricionais & 35 & $23,6 \%$ \\
\hline Pelo preço & 29 & $19,6 \%$ \\
\hline Pela marca & 15 & $10,1 \%$ \\
\hline Pelo fabricante & 7 & $4,7 \%$ \\
\hline Pela embalagem & 4 & $2,7 \%$ \\
\hline Total de entrevistados & 148 & - \\
\hline
\end{tabular}

*Pergunta de múltipla escolha, onde se teve um total de 174 respostas. Porém a análise é feita em cima do total de entrevistados, 148, pois uma pessoa pode escolher um produto por mais de um motivo.

Conforme se observa no Quadro 09, as informações do produto são obtidas na maioria das vezes em supermercados (42,5\% dos entrevistados), em segundo lugar por meio da televisão, com $20,8 \%$, seguido pela divulgação em revistas (13,7\%). Quanto a essas fontes de informação, observa-se uma diferença entre o comportamento dos consumidores e o dos não consumidores. No caso dos indivíduos que consomem o produto, mais que o dobro busca a informação no supermercado, se comparado à televisão, ao passo que entre os não consumidores do produto, o percentual é menor junto ao supermercado e bem mais próximo da informação veiculada pela TV.

Quando se analisa o local preferencial de compra das barras de cereais, observa-se que a grande maioria dos consumidores $(79,7 \%)$ adquireas nos supermercados (Quadro 10), o que pode ser indício de uma falha no sistema de distribuição do produto, concentrando-se apenas em redes de supermercados.
Quadro 09 - Onde obtém informações sobre barras de cereais.

\begin{tabular}{|c|c|c|c|}
\hline LOCAL & $\begin{array}{c}\text { NÃO } \\
\text { CONSUMIDOR }\end{array}$ & CONSUMIDOR & TOTAL \\
\hline Supermercado & $35,3 \%$ & $44,6 \%$ & $42,5 \%$ \\
\hline Televisão & $29,4 \%$ & $18,3 \%$ & $20,8 \%$ \\
\hline Revista & $13,7 \%$ & $13,7 \%$ & $13,7 \%$ \\
\hline Internet & $7,8 \%$ & $9,7 \%$ & $9,3 \%$ \\
\hline Jornal & $7,8 \%$ & $6,9 \%$ & $7,1 \%$ \\
\hline Livros & $5,9 \%$ & $4,0 \%$ & $4,4 \%$ \\
\hline Embalagem & $0,0 \%$ & $1,7 \%$ & $1,3 \%$ \\
\hline Com a família & $0,0 \%$ & $0,6 \%$ & $0,4 \%$ \\
\hline $\begin{array}{c}\text { Preparador } \\
\text { físico }\end{array}$ & $0,0 \%$ & $0,6 \%$ & $0,4 \%$ \\
\hline Total & $100,0 \%$ & $100,0 \%$ & $100,0 \%$ \\
\hline
\end{tabular}

Quadro 10 - Locais onde adquirem as barras de cereais.

\begin{tabular}{|c|c|c|}
\hline LOCAIS & $\begin{array}{c}\text { TOTAL DE } \\
\text { RESPOTAS }\end{array}$ & TOTAL \\
\hline Supermercado & 122 & $79,7 \%$ \\
\hline Farmácias & 16 & $10,5 \%$ \\
\hline Em bares e lanchonetes & 7 & $4,6 \%$ \\
\hline Em bancas de jornal & 5 & $3,3 \%$ \\
\hline Mercadinhos & 1 & $0,7 \%$ \\
\hline Distribuidora & 2 & $1,3 \%$ \\
\hline Total & 153 & $100,0 \%$ \\
\hline
\end{tabular}


Num cruzamento de dados entre idade dos consumidores e motivo de consumo, percebe-se uma tendência entre os entrevistados de mais de 55 anos em consumir o produto por ser "mais saudável" $(80 \%)$. Entre os jovens $(34,1 \%)$, o motivo destacado é "pela praticidade"; e na faixa entre 25 e 55 anos (32\% a 42\%), ressalta-se que é "para disfarçar a fome", conforme o que mostra o Quadro 11.

Quando se faz o cruzamento entre o motivo do consumo e o motivo da escolha, nota-se que o "sabor", independentemente do motivo do consumo, se sobressai dentre a maioria das opções, exceto quando o motivo diz respeito ao interesse em "manter a forma". Nesse caso, $71 \%$ dos que consomem por tal motivo atêm-se primeiramente aos "valores nutricionais" do produto.

As pessoas que consomem as barras após os exercícios físicos, ou antes deles, dividem-se entre o "sabor" e os "valores nutricionais", conforme o Quadro 12.
Quadro 11 - Relação entre a faixa etária dos consumidores e o motivo de consumo.

\begin{tabular}{|c|c|c|c|c|c|c|}
\hline \multirow{2}{*}{$\begin{array}{c}\text { MOTIVO DE } \\
\text { CONSUMO }\end{array}$} & $\begin{array}{c}15 \text { a } 24 \\
\text { anos }\end{array}$ & $\begin{array}{c}25 \text { a } 34 \\
\text { anos }\end{array}$ & $\begin{array}{c}35 \text { a } 44 \\
\text { anos }\end{array}$ & $\begin{array}{c}45 \text { a } 55 \\
\text { anos }\end{array}$ & $\begin{array}{c}\text { Mais de } \\
55 \text { anos }\end{array}$ & TOTAL \\
\hline $\begin{array}{c}\text { Para disfarçar } \\
\text { a fome }\end{array}$ & $31,7 \%$ & $\mathbf{3 2 , 0} \%$ & $\mathbf{4 2 , 1 \%}$ & $\mathbf{4 1 , 7 \%}$ & $20,0 \%$ & $34,9 \%$ \\
\hline Praticidade & $\mathbf{3 4 , 1 \%}$ & $24,0 \%$ & $28,9 \%$ & $16,7 \%$ & $20,0 \%$ & $27,4 \%$ \\
\hline $\begin{array}{c}\text { Por ser mais } \\
\text { saudável }\end{array}$ & $24,4 \%$ & $28,0 \%$ & $21,1 \%$ & $25,0 \%$ & $\mathbf{8 0 , 0} \%$ & $26,7 \%$ \\
\hline $\begin{array}{c}\text { Na hora } \\
\text { do lanche }\end{array}$ & $24,4 \%$ & $30,0 \%$ & $21,1 \%$ & $25,0 \%$ & $40,0 \%$ & $26,0 \%$ \\
\hline Por hábito & $24,4 \%$ & $16,0 \%$ & $10,5 \%$ & $8,3 \%$ & $0,0 \%$ & $15,8 \%$ \\
\hline $\begin{array}{c}\text { Devido a regime } \\
\text { e/ou dieta }\end{array}$ & $2,4 \%$ & $14,0 \%$ & $7,9 \%$ & $0,0 \%$ & $20,0 \%$ & $8,2 \%$ \\
\hline $\begin{array}{c}\text { Para manter } \\
\text { a forma }\end{array}$ & $4,9 \%$ & $2,0 \%$ & $7,9 \%$ & $8,3 \%$ & $0,0 \%$ & $4,8 \%$ \\
\hline $\begin{array}{c}\text { Antes ou } \\
\text { após exercício }\end{array}$ & $9,8 \%$ & $2,0 \%$ & $2,6 \%$ & $8,3 \%$ & $0,0 \%$ & $4,8 \%$ \\
\hline $\begin{array}{c}\text { Por alguma } \\
\text { doença }\end{array}$ & $0,0 \%$ & $0,0 \%$ & $2,6 \%$ & $0,0 \%$ & $0,0 \%$ & $0,7 \%$ \\
\hline \begin{tabular}{c} 
Outros \\
\hline$y y y y y n$
\end{tabular} & $0,0 \%$ & $0,0 \%$ & $2,6 \%$ & $0,0 \%$ & $0,0 \%$ & $0,7 \%$ \\
\hline
\end{tabular}

Uma informação importante do perfil de consumo é que os itens renda, idade e escolaridade se relacionam de uma forma interessante. Pelos dados obtidos, não existe uma classe social que consuma

Quadro 12 - Relação entre o motivo de consumo e o motivo de escolha.

\begin{tabular}{|c|c|c|c|c|c|c|c|c|c|c|}
\hline \multirow[b]{2}{*}{$\begin{array}{c}\text { MOTIVO DA } \\
\text { ESCOLHA }\end{array}$} & \multicolumn{9}{|c|}{ MOTIVO DE CONSUMO } & \multirow[b]{2}{*}{ Total } \\
\hline & $\begin{array}{c}\text { Devido a } \\
\text { regime e/ } \\
\text { ou dieta }\end{array}$ & $\begin{array}{c}\text { Para } \\
\text { manter } \\
\text { a forma }\end{array}$ & $\begin{array}{l}\text { Na hora } \\
\text { do lanche }\end{array}$ & $\begin{array}{l}\text { Por } \\
\text { hábito }\end{array}$ & $\begin{array}{c}\text { Pode } \\
\text { ser mais } \\
\text { saúdavel }\end{array}$ & $\begin{array}{c}\text { Para } \\
\text { disfarçar } \\
\text { a fome }\end{array}$ & $\begin{array}{c}\text { Antes } \\
\text { ou após } \\
\text { exercício }\end{array}$ & $\begin{array}{c}\text { Por } \\
\text { alguma } \\
\text { doença }\end{array}$ & Praticidade & \\
\hline Pelo sabor & $53,8 \%$ & $28,6 \%$ & $66,7 \%$ & $43,5 \%$ & $55,0 \%$ & $65,4 \%$ & $42,9 \%$ & $100,0 \%$ & $65,0 \%$ & $59,0 \%$ \\
\hline $\begin{array}{c}\text { Pelos valores } \\
\text { nutricionais }\end{array}$ & $30,8 \%$ & $71,4 \%$ & $25,6 \%$ & $39,1 \%$ & $32,5 \%$ & $17,3 \%$ & $42,9 \%$ & $0,0 \%$ & $5,0 \%$ & $24,8 \%$ \\
\hline Pelo preço & $15,4 \%$ & $14,3 \%$ & $12,8 \%$ & $17,4 \%$ & $17,5 \%$ & $23,1 \%$ & $0,0 \%$ & $0,0 \%$ & $22,5 \%$ & $18,0 \%$ \\
\hline Pela marca & $23,1 \%$ & $0,0 \%$ & $10,3 \%$ & $13,0 \%$ & $17,5 \%$ & $5,8 \%$ & $14,3 \%$ & $0,0 \%$ & $10,0 \%$ & $11,3 \%$ \\
\hline Pelo fabricante & $7,7 \%$ & $14,3 \%$ & $0,0 \%$ & $4,3 \%$ & $7,5 \%$ & $3,8 \%$ & $0,0 \%$ & $0,0 \%$ & $5,0 \%$ & $4,5 \%$ \\
\hline Pela embalagem & $0,0 \%$ & $0,0 \%$ & $2,6 \%$ & $4,3 \%$ & $0,0 \%$ & $3,8 \%$ & $14,3 \%$ & $0,0 \%$ & $5,0 \%$ & $3,2 \%$ \\
\hline $\begin{array}{l}\text { Total por motivo } \\
\text { de consumo }\end{array}$ & $100,0 \%$ & $100,0 \%$ & $100,0 \%$ & $100,0 \%$ & $100,0 \%$ & $100,0 \%$ & $100,0 \%$ & $100,0 \%$ & $100,0 \%$ & $100,0 \%$ \\
\hline
\end{tabular}


mais do que a outra. Isso demonstra que o produto é consumido por todas as classes sociais e o que pesa na escolha é definido por uma tendência, pois, após o cruzamento entre os dados da idade dos consumidores e o motivo de consumo, resulta que:

- para os idosos a palavra "saudável" está diretamente associada ao produto;

- para os jovens a palavra "praticidade" está diretamente associada ao produto; e

- para os de meia idade a "praticidade" aliada com o desejo de "disfarçar a fome" são os motivos que se destacam.

Este cruzamento de dados entre a idade dos consumidores e o motivo do consumo mostra que cada público vê o produto de forma diferente, e que se influenciam pelas características que mais lhes interessam.

Quando se relaciona o consumo com as fontes onde os consumidores obtêm informações sobre esses produtos, observa-se que, no geral (42,8\% dos consumidores), eles buscam a informação nos supermercados, possivelmente por ser o local de maior disponibilidade do produto. O referido percentual é mais do que o dobro quando comparado à segunda opção de fonte, que é a televisão ( $20,8 \%$ dos consumidores). No entanto, existe uma diferença entre o grupo dos consumidores e o dos não consumidores. A busca de informação nos supermercados é bem mais significativa no grupo de consumidores do produto, enquanto que no grupo de não consumidores ela se realiza tanto nos supermercados quanto pela televisão (35\% e $29 \%$ respectivamente). Tal comportamento pode mostrar que, quando a informação é buscada mais próxima ao produto, pode induzir à efetivação da compra, e que a TV, apesar de ser um meio ótimo de divulgação, distancia os não consumidores do produto, possivelmente pelo fato deste produto ter sua compra efetuada mais na forma de "impulso" do que como um produto de consumo rotineiro.

Assim sendo, com vista às tendências observadas, a forma mais indicada para a promoção das barras de cereais seria nos pontos de venda, por meio das ilhas de produto, displays, degustação (principalmente) ou flyers, em lugar de se fazer um investimento (que às vezes é mais oneroso) em propagandas televisivas. Caso se utilize a mídia televisiva como meio de comunicação do produto, deve-se observar o horário e o direcionamento da propaganda de forma a atingir o público alvo certo.

\section{Conclusões}

O objetivo deste trabalho era descrever o comportamento do consumidor e do não consumidor de barras de cereais, identificando o público ao qual a promoção do produto deve ser direcionada de forma a estimular o seu consumo. Das 232 pessoas entrevistadas, $63,8 \%$ consomem barras de cereais, e as mulheres $(73,8 \%)$ consomem mais deste produto que os homens $(51,9 \%)$.

Sob o ponto de vista do estado civil, os dados não mostram nenhuma tendência de consumo.

No que diz respeito às faixas etárias, a proporção do público consumidor deste produto não se diferencia. Possivelmente isso ocorra devido à ideia passada pelo produto de ser um alimento natural, atingindo assim tanto um público mais idoso, como o público jovem.

O nível de renda dos entrevistados não mostra uma forte tendência para o consumo preferencial por algum dos níveis mais especificamente.

Os consumidores com mais alto grau de escolaridade, ou seja, com no mínimo $2^{\circ}$ grau, são os que mais consomem o produto, ao passo que, dentre os que possuem apenas $1^{\circ}$ grau completo, a maioria não consome.

A realização de exercícios físicos não influencia no consumo de barras de cereais.

Analisando os motivos que levam ao consumo de barras de cereais, observa-se que a maioria dos consumidores procura as barras de cereais como um alimento "para disfarçar a fome", seguido por três outros itens: "por ser mais saudável", "sem motivo" e "na hora do lanche".

A compra do produto é impulsionada pelo "sabor", seguido pelos "valores nutricionais". O preço, a marca, o fabricante e a embalagem mostraram uma baixa interferência na hora da decisão de compra do produto pelo consumidor.

O local preferencial de compra das barras de cereais são os supermercados, o que pode ser um indício de uma falha no sistema de distribuição deste produto para outros pontos de venda.

Os itens renda, idade e escolaridade se relacionam de uma forma interessante, pois não existe 
uma classe social que consuma mais do que a outra. Isso demonstra que o produto é consumido por todas as classes sociais e o que pesa na escolha é definido por uma tendência.

Após o cruzamento entre os dados da idade dos consumidores e o motivo de consumo, obtevese que, para os idosos, a palavra "saudável" está diretamente associada ao produto, enquanto junto aos jovens e pessoas de meia idade a "praticidade" e o desejo de "disfarçar a fome" se sobressaem.

Quando se relaciona o consumo com as fontes onde os consumidores obtêm informações, observase que o índice de obtenção informacional junto aos supermercados é bem mais significativo no grupo de consumidores do produto. Já no grupo de não consumidores a busca por informações sobre o produto é realizada tanto nos supermercados quanto na televisão. Isto pode demonstrar que a TV, apesar de ser um meio ótimo de divulgação, distancia os não consumidores do produto, possivelmente pelo fato deste produto ter sua compra efetuada na forma mais de "impulso" do que como um produto de consumo rotineiro.

Assim sendo, com vista a estas tendências observadas, a forma mais indicada para promoção deste produto seria nos pontos de venda, por meio das ilhas de produto, displays, degustação (principalmente) ou flyers, em vez de se fazer um investimento (possivelmente mais oneroso) em propagandas televisivas.

\section{Referências}

AMERINE, M. A.; PANGBORN, R. M.; ROESSLER, E. B. Principles of sensoy evaluation of food. London: Academic Press, 1965.

MELLO, B. Especial o que o consumidor quer. Relacionamento é a base. Mundo do marketing. Disponível em: <http://www.mundodomarketing.com.br/2006/ver_reportagens.asp? cod=392>. Acesso em: 05 fev. 2007.

OLIVEIRA, M. O que o consumidor quer dos produtos. Mundo do marketing. Disponível em: <http:// www.mundodomarketing.com.br/2006/ver_reportagens. asp?cod=405> Acesso em: 13 fev. 2007.

TRIOLA, M. Introdução à estatística. 7.ed. São Paulo: L.T.C., 1999. 
Anexo 1: Questionário aplicado na pesquisa de consumo de barras de cereais. (Aprovado pelo Comitê de Ética em Pesquisa em Humanos e Animais da Universidade Tuiuti do Paraná).

1) VOCÊ É CONSUMIDOR DE BARRAS DE CEREAIS?
( ) $\operatorname{sim}$
( ) não

Por quê?

2) SEXO:

( ) feminino ( ) masculino

3) ESTADO CIVIL

( ) solteiro ( ) casado ( ) divorciado

( ) vivendo juntos ( ) outros

4) FAIXA ETÁRIA:

( ) 15 a 24 anos ( ) 25 a 34 anos
( ) 35 a $44 \operatorname{anos}($ ) 45 a 55 anos
( ) $>55$ anos

5) PESO (kg):

ALTURA (metros):

IMC= $\mathrm{Kg} / \mathrm{m}^{2}$

6) RENDA:

$\begin{array}{ll}\text { ( ) até } 1 \mathrm{sm} & \text { ( ) de } 1 \text { a } 2 \mathrm{sm} \\ \text { ( ) de } 2 \text { a } 3 \mathrm{sm} & \text { ( ) de } 3 \text { a } 5 \mathrm{sm} \\ \text { ( ) de } 5 \text { a } 10 \mathrm{sm} & \text { ( ) de } 10 \text { a } 20 \mathrm{sm} \\ \text { ( ) mais de } 20 \mathrm{sm} & \end{array}$

7) GRAU DE INSTRUÇÃO:

( ) $1^{\circ}$ grau incompleto ( ) $1^{\circ}$ grau completo

( ) $2^{\circ}$ grau incompleto ( ) $2^{\circ}$ grau completo

( ) $3^{\circ}$ grau incompleto ( ) $3^{\circ}$ grau completo

( ) nenhuma formação

8) VOCÊ FAZ ALGUM EXERCÍCIO FÍSICO?

( ) sim, frequento academia

( ) sim, faço caminhadas regularmente

( ) às vezes faço exercício/caminhada

( ) não faço exercicio físico
9) VOCÊ COSTUMA CONSUMIR BARRA DE CEREAL (MÁXIMO 2 ALTERNATIVAS):

( ) devido a regime/dieta

( ) para disfarçar a fome

( ) para manter a forma

( ) antes/após exercício físico

( ) na hora do lanche

( ) por alguma doença

( ) por hábito ( ) praticidade

( ) por ser mais saudável

( ) outros

10) ONDE VOCÊ OBTÉM AS INFORMAÇÕES SOBRE ESSE PRODUTO?

( ) tv ( ) jornal ( ) revista

( ) internet ( ) livros

( ) supermercado/bar

( ) outros

11) COMO VOCÊ COSTUMA ESCOLHER SUA BARRA DE CEREAL?

( ) pelo preço

( ) pelos valores nutricionais

( ) design da embalagem

( ) pela marca ( ) pelo sabor/textura

( ) pelo fabricante

12) QUAL É A BARRA QUE VOCÊ COSTUMA CONSUMIR COM FREQUÊNCIA?

13) ONDE COSTUMA COMPRAR SUA BARRA DE CEREAL?

( ) no supermercado

( ) em bancas de jornal

( ) farmácias

( ) em bares e lanchonetes

( ) mercadinho

14) O QUE FALTA NAS BARRAS DE CEREAIS QUE EXISTEM NO MERCADO? 
Of. CEP-UTP n. ${ }^{\circ} 0079 / 2007$

Sr. Pesquisador

O Comitê de Ética em Pesquisa em Humanos e Animais da Universidade Tuiuti do Paraná, CEP-UTP, após apreciação do Projeto de pesquisa de sua autoria, intitulado: "O perfil do comportamento do consumidor de barras de cereais de Curitiba. ”, considerou-o APROVADO.

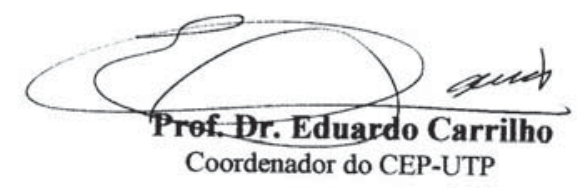

$\mathrm{Ilm}^{\mathrm{a}}$. Sr. ${ }^{\mathrm{a}}$

Prof. Dr. ${ }^{a}$ Cláudia H. Degáspari. 